\title{
An effectiveness evaluation of the palmar fascia irradiation of patients suffering from Dupuytren's disease
}

\author{
Tomasz Latusek , Leszek Miszczyk¹, 2, Grzegorz Gierlach³, Piotr Zając³
}

Introduction. Dupuytren's disease (DD) is a fibroproliferative disorder of an unknown etiology manifested by a progressive contracture of fingers. The basic method of the treatment is surgery. Among non-surgical treatments, radiotherapy $(\mathrm{RT})$ represents a relevant method.

The aim of the study was to evaluate the efficacy of palmar fascia irradiation in patients with Dupuytren's Disease. Material and methods. The research included a group of 117 patients with Dupuytren's disease irradiated in the Department of Radiotherapy in the Maria Skłodowska-Curie Memorial Cancer Center and Institute of Oncology in Gliwice. Patients' medical records from the Institute of Oncology in Gliwice and the Provincial Hospital of Orthopedics and Trauma Surgery in Piekary Śląskie have been analysed retrospectively.

The following were assessed: smoking history and the subjective evaluation of the effect of the therapy and its side effects before irradiation and check-up visits.

All patients were irradiated to a total dose of 21 Gy given in 7 fractions.

Results. After the RT, 35\% of patients showed an improvement, in 58\% of patients the disease progress stopped, whereas $7 \%$ of patients reported a deterioration.

During the observation period, $7.5 \%$ of patients noted a deterioration of the contracture or the topical condition, in $35 \%$ stagnancy was observed, and $57.5 \%$ of patients showed a reduction of the contracture and an improvement in the topical condition.

After the RT, $87.5 \%$ of patients had no side effects, in $7.5 \%$ there was a slight skin erythema, $2.5 \%$ had superficial epidermis exfoliation, and $2.5 \%$ reported dry skin.

Conclusions. The obtained results allow one to conclude that palmar fascia irradiation is an effective method of treatment for patients with Dupuytren's disease and it is characterised by a low proportion of complications.

NOWOTWORY J Oncol 2017; 67, 3: 162-167

Key words: Dupuytren's Disease, radiotherapy, Dupuytren's Contracture

\section{Introduction}

Dupuytren's disease is a fibroproliferative disorder of an unknown aetiology [1, 2]. It is manifested by a progressive contracture of the fingers, which impairs hand function. This condition, in spite of its unknown aetiology, has been known about for about 400 years. The first reports were provided by Felix Platter from Basel around 1614 [3, 4]. He believed that this disease was caused by shortening of the tendons of the finger flexors. Then, in about 1777, Henry Cline proposed fasciotomy as a method of treatment. Yet the name of the disease comes from Guillaume Dupuytren, who described its course in 1831 [3, 4].

\footnotetext{
${ }^{1}$ Radiotherapy Department, Maria Skłodowska-Curie Memorial Cancer Center and Institute of Oncology, Gliwice, Poland ${ }^{2}$ Bone Tumor Unit, District Hospital of Orthopedics and Trauma Surgery, Piekary Śląskie, Poland Maria Skłodowska-Curie Memorial Cancer Center and Institute of Oncology, Gliwice, Poland ${ }^{3}$ Hand Surgery Department, District Hospital of Orthopedics and Trauma Surgery, Piekary Śląskie, Poland
} 
DD is a relatively rare condition; affecting $1-2 \%$ of the population. Most frequently, it affects men $[1,3,5,6]$. The palmar fascia is shortened and thickened, which, in consequence, leads to a permanent and irreversible flexed contracture of the fingers $[3,7]$.

The risk factors comprise genetic predispositions race, gender, age, as well as environmental factors. Genetic factors play some role in the occurrence of $\mathrm{DD}$, yet, similar to its pathogenesis, they still remain largely unexplained. The manner of inheritability seems to be heterogenic, most frequently it is dominating autosomal with a variable penetration, whilst more rarely it can be recessive autosomal or mitochondrial. Genetic studies showed some relationship between DD and chromosomes [6, 8-10]. The aberrations of the genes participating in the Wnt/beta-catenin signalling pathway seem to play a key role in the pathogenesis of the disease [11].

The probability of occurrence of the disease increases with age and is higher among men. Among the environmental risk factors, researchers point to tobacco smoking, alcohol, trauma, DM, epilepsy and the use of anti-convulsive drugs as well as exposure to vibrations $[3,5-7,12]$.

Duputren's disease is a complex condition with a patomechanism that is largely unknown. The occurrence of contractures is related to the disorders of the connective tissue function. Both cells and biochemical substances, such as growth factors and the substances involved in the cellular signalling pathways, take part in this process [10, 13-15].

Physiologically, the correct remodelling of the extracellular matrix plays a key role in the process of fast and effective repair of damaged tissues. At the end of the physiological process of wound healing, myofibroblasts disappear as a result of apoptosis, yet once the control of this process is impaired, the beneficial processes of remodelling might lead to organ deformity and loss of function [13].

Within the course of DD there is an uncontrolled and excessive proliferation of fibroblasts and the storage of collagen, mainly type III and IV, and glycosaminoglycans $[3,10,14]$. Molecular mechanisms underlying the disease are still poorly explained. One of them is believed to be the disorder of metalloproteinases (MMP) and tissue inhibitors of metalloproteinases (TIMP) ratio. MMP-2 and MMP-14 proteases are pointed as having a key function in this process, and thus, they might be used as markers or a potential therapeutic target of medication [9].

A characteristic feature of DD is the presence of nodules. The Fibroblasts, which build the nodules reveal an increased response to mechanical strain and larger contractility. This is connected with an increase in MMP-1, -2, -9 levels and a decrease of TIMP expression [16].

In addition, the role of blood vessels in the pathogenesis of DD is suggested. Proliferating cells are in the nearest vicinity of the vessels and are located mainly in the myo- fibroblasts layer. The vicinity of small blood vessels is the area with an increased presence of growth factors, which stimulate the proliferation, that, in connection with an advantageous composition of extracellular matrix, provides an environment which sustains proliferation [17]. According to recent reports, myofibroblasts play a leading role in the patomechanism of tendon contractures $[12,18]$. It is suggested that calcium plays a key role not only in the mechanism of myofibroblast contraction, but also in the process of inter-and extracellular signalling [13]. Among other signalling disorders, there is also a Wnt/beta-catenin signalling disruption [11].

The lesion in DD are located along the lines of longitudinal tensions of the hand $[3,19,20]$. This is caused by the shortening of the structure of the palmar fascia. The lesions affect most frequently finger 5, 4, 3 and then the thumb and index finger [21, 22]. The lesions usually affect both hands, yet the symptoms are asymmetrically intensive [23, 24]. As a consequence, a permanent finger contracture occurs and, sometimes, even a deformity of the metacarpophalangeal joints and metacarpophalangeal joints. The course of the disease may be divided into three stages: the initial one in which the nodules are dominating, the involution stage - the differentiation of the cells to myofibroblasts and the residual stage in which the collagen fibres are present [1, $2,25,26]$.

The basic treatment method is surgical intervention. Non-surgical methods of contracture treatment comprise pharmacology, ultrasounds, physiotherapy and radiotherapy (RT). In publications there are also references to experimental methods, such as Clostridium histoliticum collagenase injections, although the long-term safety and time before the recurrence of the condition after this procedure still requires further evaluation [14].

Among the most recent reports, there is a continually growing interest in the radiotherapy of non-oncological conditions, including DD $[27,28]$. The use of irradiation and the application of ionising radiation is universally known and has become an element of the interdisciplinary approach to the treatment of many diseases, including Dupuytren's disease $[1,2,25,26]$. The efficacy of RT depends on the stage of the disease and is the highest in the early stage $[1,2,25,26]$.

The reports described irradiation with the use of fractional dose of 2-3 Gy of the total dose of 15-21 Gy. The two most frequently applied regimes of fractionating the irradiation dose were: 7 fractions up to a total dose of $21 \mathrm{~Gy}$ or 5 fractions up to the total dose of $15 \mathrm{~Gy}$ in two series $[25,26,28]$.

The objective of the work was to evaluate the efficiency and occurring complications after the irradiation of the palmar fascia in the patients affected by Dupuytren's disease. 


\section{Material and methods \\ Material}

The analysis comprised 117 patients irradiated between 2011 and 2015 at the Radiotherapy Department in Gliwice. The study group comprised 78 men and 39 women with Dupuytren's disease in the nodular or contracture stages of DD. The patients included in the study were irradiated up to a dose of $21 \mathrm{~Gy}$ administered in 7 fractional doses. In the process of preparation for treatment, all the patient thermoplastic immobilisations were performed in order to stabilise the limb as well as computer tomography in order to plan the treatment process (Fig. 1 and 2).

The age of the patients varied from 30 to 82 years (mean 61, median: 62). Before the onset of RT, 35 subjects did not report any complaints and oedema was observed in 7 subjects, 20 subjects reported a limitation of mobility, 3 patients experienced a sensation of tightness, one patient had difficulties in squeezing the hand; whereas 24 subjects experienced pain, 9 subjects - numbness, $61.5 \%$ had contractures; in 54\% patients both hands were affected and $74 \%$ had nodules.

$58 \%$ of patients had a smoking history and $20 \%$ patients smoked during treatment.

$84 \%$ were not previously (before RT) treated, $1 \%$ subjects underwent laser therapy, 13\% were surgically treated, $1 \%$ with ultrasounds and in $1 \%$ steroid therapy was applied in the form of local injections. During RT, the patient did not undergo any other therapies.
The study visit at which the effects of RT were evaluated took place after diverse periods of time $(M=4.8$ months; $S D \pm 6.11$ ). The results of the first visit were taken into consideration. The shortest time span between the end of RT and the visit was one month and the longest -34 months.

\section{Methods}

The medical files of the Oncology Institute in Gliwice and District Hospital of Orthopedics and Trauma Surgery in Piekary Śląskie were analysed.

The collected data comprised the information from the periods before the irradiation and from study visits, smoking history, current tobacco use, pain complaints, hand function disorders and limitation of mobility, previous treatments and prospective complications. With regards to the retrospective character of the analysis, it was impossible to apply Tubian's scale, as the majority of patients were not evaluated according to this scale during the study visits. The patients included in the study were in the early stages of $D D$, hence the evaluation of the efficacy of irradiation in their therapy seemed justified. On the basis of the data in the patients' histories, the efficacy of the applied RT was evaluated changes regarding the manual function, the presence of contracture and the prospective occurrence of new complaints - complications after treatment. The improvement was defined as a decrease in the size of nodules, reduction of contracture or the improvement of manual function.

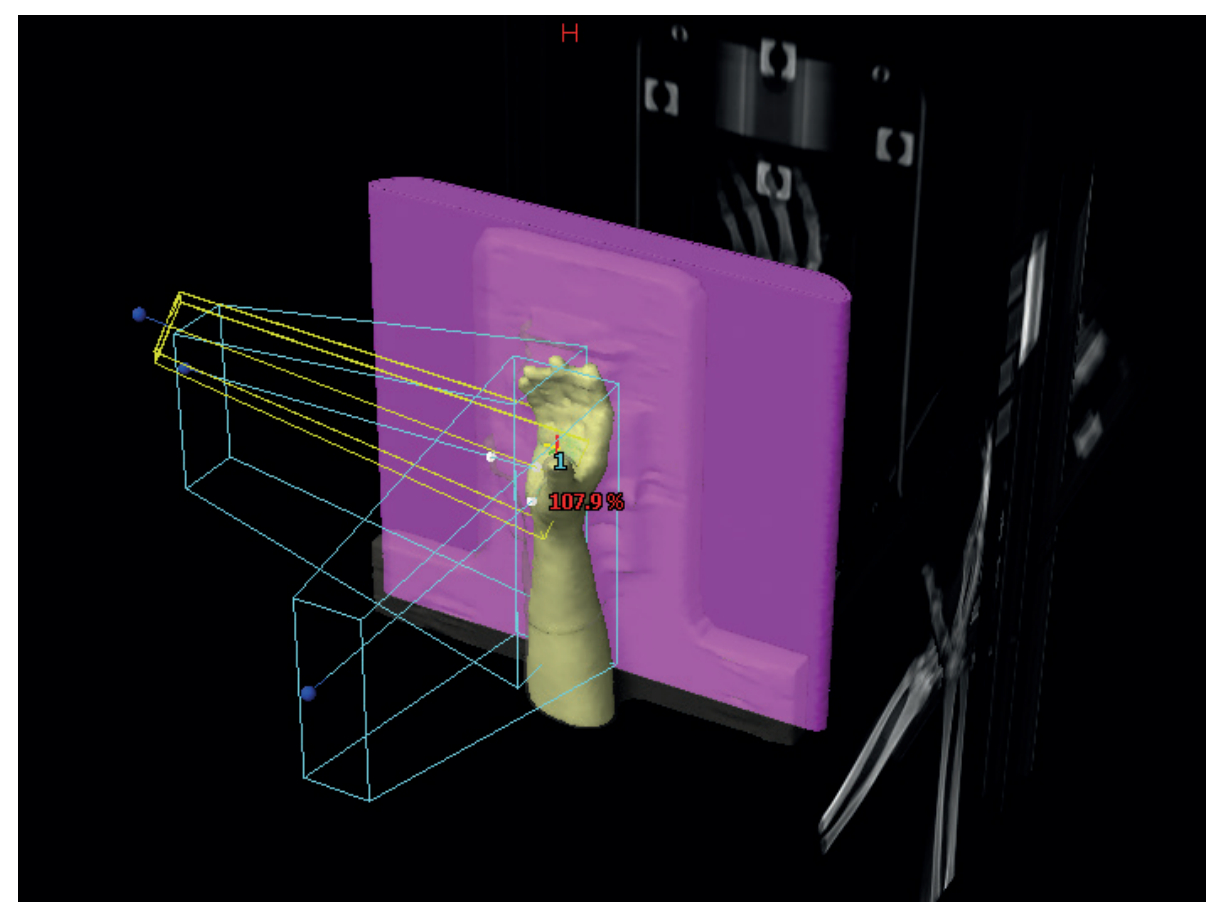

Figure 1. A three-dimensional reconstruction of a hand of the patient stabilised in a therapeutic position 


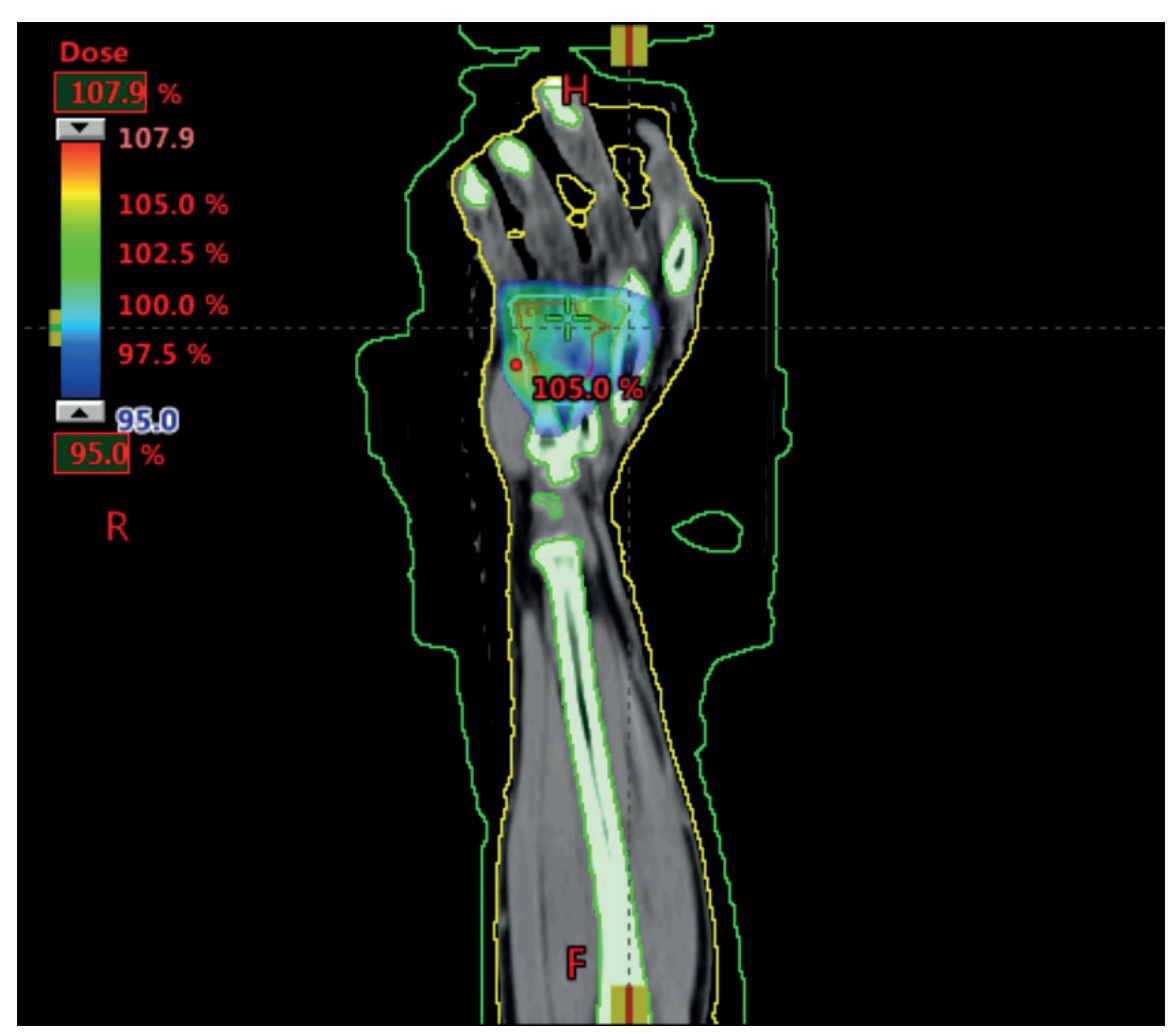

Figure 2. Dose distribution in the target volume. Frontal section of the patient's hand

The statistical analysis was performed with the t-Student test. Also the relationship between smoking (regarded as a risk factor) and reported complaints and the presence of contractures was analysed. The differences in the disease symptoms before and after RT were compared. In total, the files of 117 patients were analysed.

\section{Results}

The information from at least one visit was available in 117 cases. During the analysis it was found that some patients failed to turn out for the next visit or appeared at a different date than appointed.

Immediately after RT, some improvement was observed in $35 \%$ cases, in $58 \%$ the local condition was stable whilst $7 \%$ of patients reported a deterioration of the local condition. During the observation period, in $57.5 \%$ of cases, an improvement of the local condition was observed; in 35\% of cases - a stagnation of the local condition was seen and in $7.5 \%$ - a deterioration of the local condition.

In the subjects in whose case a follow-up visit took place later ( $M=6.6$ months), an improvement of the local condition was seen more frequently (the difference was statistically insignificant: $t=-1.73 ; p=0.9$ ) than in those cases where no improvement was observed ( $M$ time period to the follow-up visit $=2.86$ months).

In $87.5 \%$ of subjects there were no skin problems after RT, $7.5 \%$ had some erythema, $2.5 \%$ of patients had superfi- cial epidermal exfoliation and $2.5 \%$ reported palmar dryness. The patients in whose cases improvement was observed were younger at the moment of discharge $(M=59.3$ years; $\mathrm{SD} \pm 8.9)$ than those in whose case no improvement was seen $(M=63.7$ years; $S D \pm 10.3)$.

The comparison of smokers and non-smokers among patients with regards to their condition after RT did not reveal any significant differences $(p>0.05)$. This concerned both the patients with a smoking history only and current active smokers $(p>0.05)$.

\section{Discussion}

With regards to the unknown aetiology and complex character of Dupuytren's disease, its causative treatment is currently impossible. The currently applied therapies are symptomatic. A leading role in the treatment of DD is still played by surgical interventions, yet this way of treatment is by no means perfect as surgery is connected with a risk of complications - at a level of $20 \%$ [3, 29-31]. Both the intra-operative complications, such as damage of nerves or blood vessels and post-surgical complications (i.e. skin necrosis or haematoma) must be taken into consideration as well as remote complications, which might occur as a result of the lack of rehabilitation or its incorrect management [3, 30-32].

Apart from the risk of complications, another significant problem concerning the treatment of DD is the recurrent 
character of the disease. Even surgery does not exclude the possibility of recurrence. In various reports, recurrence is present in $26-80 \%$ of cases [3, 29-31].

Other methods of DD treatment comprise radiotherapy. Although the irradiation of the palmar fascia is not the basic treatment approach, it is a generally acknowledged and widely applied method, especially in the early stage of DD $[1,2,25,26]$. This method utilises the anti-inflammatory and anti-proliferative effect of RT. The majority of subjects within the study material were neither operated on nor treated with any other methods apart from RT — the patients previously treated with other methods, ended their treatment before RT. They were referred for RT on account of the lack of any progress of previous treatments. Also, the initial evaluation of the condition of patients included in the study took place after treatment with methods other than RT, hence it was the use of RT that contributed to the improvement or the lack of deterioration (stagnation) of the health condition of the patients.

The results obtained within the study must be regarded as partly compliant with the published data concerning DD. Both with regards to epidemiology and risk factors, the picture was congruent with the reports of other authors concerning this issue [5,6], yet the very occurrence of a given risk factor in a given group should not preclude its role in the pathogenesis of the disease. Out of the risk factors of developing DD mentioned in published data was smoking $[3,5-7,12]$. In the analysed material, one half of the subjects smoked, yet no significant correlation between smoking and the course of the disease or the treatment response was found. This concerned both the subjects who were not smoking during treatment, but had a smoking history as well as current active smokers.

In this study, the evaluation of the efficiency of RT had a subjective character. In the majority of subjects, no disease progression was observed during the follow-up visit (58\% of patients), in $35 \%$ of patients some improvement of the hand function was observed. Radiotherapy of patients with DD seems therefore an effective method of treatment. Only $7 \%$ of patients reported some deterioration of the hand function after the application of RT. The obtained results concerning the efficiency are concordant with the most recently published reports concerning this issue [37]. In these patients the contracture was progressing gradually, which reduced the hand function or, sometimes, the nodules' size was increasing.

Among other parameters, some slight difference was observed between the age of the patients and the response to RT. The subjects in whose case some improvement was observed were younger than those where no improvement took place. The observed difference seems to be too small to draw any conclusions, concerning the efficiency of RT in the treatment of $\mathrm{DD}$, as conditioned by the age of the patients.

Skin reaction, after irradiation, occurred only in $12.5 \%$ of patients - in $87.5 \%$ of cases no skin lesions were observed, which is indicative of a low treatment toxicity.

In spite of a long history of radiotherapy use in the treatment of non-oncological diseases, the application of irradiation in this group of patients still seems controversial and raises some concerns. The controversies concern first of all the risk of occurrence of secondary cancers, in particular among younger patients with a longer expected survival period. However, the interpretation of this data with regards to the differences in the irradiation technique with regards to the contemporary clinical practice seems quite problematic. Modern radiotherapy methods, applying patient stabilisation and precise definition of the target on the basis of computed tomography, guarantee a high precision of dose application and the protection of healthy tissues $[33,34]$. Currently there are specific guidelines which define indications and irradiation strategies in the treatment of non-oncological diseases [36-38]. In accordance with the guidelines of the International Commission on Radiological Protection, cancer prevalence in the area of ionising radiation increases linearly and amounts to 5.5\% per 1 Sv dose $[39,40]$. In the opinion of Broerse, the risk of a secondary cancer after radiotherapy used in the treatment of non-oncological diseases in young subjects is low and totals $0.3-0.7 \%$ [41].

In the analysed group, no cases of secondary cancers were observed after the use of irradiation in the treatment.

\section{Conclusions}

The obtained results allow for concluding that radiotherapy of the palmar fascia is an effective method of treating patients with Dupuytren's disease, in particular at the early stage of the disease; this method is also characterised by a low rate of complications. It was also observed that in patients with some improvement of the hand function, the follow-up visit took place at a later date (about 6 months after the treatment). This seems important from the point of view of the organisation of follow-up visits after RT.

Conflict of interests: none declared

\section{Tomasz Latusek, MD}

Radiotherapy Department

Maria Skłodowska-Curie Memorial Cancer Center

and Institute of Oncology

Wybrzeże Armii Krajowej 15

44-101 Gliwice, Poland

e-mail:Tomasz.Latusek@io.gliwice.pl

Received: 26 Oct 2016

Accepted: 29 May 2017 


\section{References}

1. Seegenschmiedt $\mathrm{MH}$, Micke $\mathrm{O}$, Niewald $\mathrm{M}$ et al. DEGRO guidelines for the radiotherapy of non-malignant disorders: part III: hyperproliferative disorders. Strahlenther Onkol 2015; 191: 541-548.

2. Adamietz B, Keilholtz L, Gruenert J et al. Radiotherapy in early stage Dupuytren's disease. Long-term results after a median follow-up period of 10 years. Strahlenther Onkol 2001; 177: 604-610.

3. Kobus K, Wójcicki P, Dydymski T et al. Evaluation of treatment results of patients with Dupuytren's contracture - our clinical experience. Ortopedia Traumatol Rehabilit 2007; 9: 134-140.

4. Elliot D.The early history of Dupuytren's disease. Hand Clin 1999; 15: 1-19.

5. Ross DC. Epidemiology of Dupuytren's disease. Hand Clin 1999; 15: 53-62.

6. Yi IS, Johnson G, Moneim MS. Etiology of Dupuytren's disease. Hand Clin 1999; 15: 43-51.

7. Rayan GM. Dupuytren disease: Anatomy, pathology, presentation, and treatment. J Bone Joint Surg Am 2007; 89: 189-198.

8. Michou L, Lermusiaux JL, Teyssedou JP et al. Genetics of Dupuytren's disease. Joint Bone Spine 2012; 79: 7-12.

9. Ten Dam EJ, van Beuge MM, Bank RA et al. Further evidence of the involvement of the Wnt signaling pathway in Dupuytren's disease. J Cell Commun Signal 2016; 10: 33-40.

10. Follonier Castella L, Gabbiani G, McCulloch CA et al. Regulation of myofibroblast activities: Calcium pulls some strings behind the scene. Exp Cell Res 2010; 316: 2390-2401.

11. Wilkinson JM, Davidson RK, Swingler TE et al. MMP-14 and MMP-2 are key metalloproteases in Dupuytren's disease fibroblast-mediated contraction. Biochim Biophys Acta 2012; 1822: 897-905.

12. Verhoekx JS, Beckett KS, Bisson MA et al. The mechanical environment in Dupuytren's contracture determines cell contractility and associated MMP-mediated matrix remodeling. J Orthop Res 2013; 31: 328-334.

13. Viil J, Maasalu K, Mäemets-Allas K et al. Laminin-rich blood vessels display activated growth factor signaling and act as the proliferation centers in Dupuytren's contracture. Arthritis Res Ther 2015; 17: 144. DOI. 10.1186/s13075-015-0661-y.

14. Shih B, Bayat A. Scientific understanding and clinical management of Dupuytren disease. Nat Rev Rheumatol 2010; 6: 715-726.

15. Ratajczak K, Augoff K, Gosk J et al. Lactate dehydrogenase isoenzymes in Dupuytren's contracture. Adv Clin Exp Med 2007; 16: 205-211.

16. Tomasek JJ, Vaughan MB, Haaksma CJ. Cellular structure and biology of Dupuytren's disease. Hand Clin 1999; 15: 21-34.

17. Badalamente MA, Hurst LC. The biochemistry of Dupuytren's disease. Hand Clin 1999; 15: 35-42.

18. Musumeci M, Vadala G, Russo F et al. Dupuytren's disease therapy: targeting the vicious cycle of myofibroblasts? Expert Opin Ther Targets 2015; 19: 1677-1687.

19. Hueston J. Dupuytren's contracture. J Hand Surg [Br] 1993; 18: 806

20. Forsman $M$, Kallioinen $L$, Kallioinen $M$ et al. Dupuytren's contracture; increased cellularity - proliferation, is there equality? Scand J Surg 2005; 94: 71-75.

21. Kobus K, Wójcicki P, Dydymski T et al. Ocena wyników leczenia chorych z przykurczem Dupuytrena w oparciu o analizę materiału własnego. Ortopedia Traumatol Rehabilit 2007; 9: 134-140.

22. Bednarek M, Trybus M, Pokrowiecki W et al. Ocena wpływu operacyjnego leczenia przykurczu Dupuytrena na poprawe funkcji ręki w oparciu o badania przeprowadzone z zastosowaniem kwestionariusza DASH (Disability of the Arm, Shoulder and Hand) - doświadczenia własne. Przegl Lek 2013; 70: 893-899.
23. Seegenschmiedt MH, Makoski HB, Haase W et al. Radiotherapy of non-malignant diseases: principles and recommendations. Rontgenpraxis $2000 ; 52: 371-377$.

24. Keilholz L, Seegenschmiedt MH, Born AD et al. Radiotherapy in the early stage of Dupuytren's disease. The indications, technic and long-term results. Strahlenther Onkol 1997; 173: 27-35.

25. Seegenschmiedt MH. Morbus Dupuytren / Morbus Ledderhose. In: Seegenschmiedt MH, Makoski HB, Trott KR et al. (eds.). Radiotherapy fornon-malignant disorders: Contemporary concepts and clinical results. Berlin; Heidelberg: Springer Verlag, 2008: 161-191.

26. Seegenschmiedt MH, Keilholtz L, Wielpuetz M et al. Long-term outcome of radiotherapy for early stage Dupuytren's disease: a phase III clinical study. In: Eaton C, Seegenschmiedt MH, Bayat A et al. (eds.). Dupuytren's disease and related hiperproliferative disorders: principles, research, and clinical perspectives. Berlin; Heidelberg: Springer Verlag, 2012: 349-371.

27. Ott O, Hertel S, Gaipl US et al. The Erlangen dose optimization trial for radiotherapy of benign painful shoulder syndrome. Long-term results. Strahlenther Onkol 2014; 190: 349-398.

28. Ott O, Jeremias C, Gaipl US et al. Radiotherapy for benign calcaneodynia: long-term results of Erlangen Dose Optimization (EDO) trial. Strahlenther Onkol 2014; 190: 671-675.

29. Mafi R, Hindocha S, Khan W. Recent surgical and medical advances in the treatment of Dupuytren's disease - A systematic review of the literature. Open Orthop J 2012; 6 (M9): 77-82.

30. Freeman AG. Topical treatment for Dupuytren's contracture. Lancet 1995; 345: 382.

31. Armstrong JR, Hurren JS, Logan AM. Dermofasciectomy in the management of Dupuytren's disease. J Bone Joint Surg Br 2000; 82: 90-94.

32. Boyer Ml, Gelberman RH. Complications of the operative treatment of Dupuytren's disease. Hand Clin 1999; 15: 161-166.

33. Berrington de Gonzalez A, Gilbert E, Curtis R et al. Second solid cancers after radiation therapy: a systematic review of the epidemiologic studies of the radiation dose-response relationship. Int J Radiat Oncol Biol Phys 2013; 86: 224-233.

34. Mazonakis $M$, Damilakis J. Cancer risk after radiotherapy for benign diseases. Phys Med 2017; p II: S1120-1797: 30015-30017.doi.10.1016/j. ejmp.2017.01.014.

35. Winkfield KM, Bazan JG, Gibbs IC et al. Nonmalignant diseases. In: Halperin EC, Wazer DE, Perez CA et al. (eds.). Perez and Brady's principles and practice in radiation oncology. Philadelphia: Lippincott Williams \& Wilkins, 2013: 1729-1751.

36. Seegenschmiedt MH, Micke O, Muecke R. Radiotherapy for non-malignant disorders: state of the art and update of the evidence-based practice guidelines. Br J Radiol 2015; 88: 20150080.

37. Leer JW, Van Houtte P, Seegenschmiedt H. Radiotherapy of non-malignant disorders: where do we stand? Radiother Oncol 2007; 83: 175-177.

38. Taylor R, Hatfield P, McKewon S et al. A review of the use of radiotherapy in the UK for the treatment of benign clinical conditions and benign tumours. London: The Royal College of Radiologists, 2015.

39. ReichI B, Block A, Schafer U et al. DEGRO practical guidelines for radiotherapy of non-malignant disorders. Part I: physical principles, radiobiological mechanisms, and radiogenic risk. Strahlenther Onkol 2015; 191: 701-709.

40. Authors on behalf of ICRP, Stewart FA. Akleyev AV, Hauer-Jensen M et al. ICRP publication 118: ICRP statement on the tissue reactions and early and late effects of radiation in normal tissues and organs-threshold doses for tissue reactions in a radiation protection context. Ann ICRP 2012; 41:1-322.

41. ESTRO-EORTC Meeting on Radiation for Benign Disease: Current Status and Possible Perspectives. Brussels, Belgium, 10-13 Oct. 1999. Abstracts. Radiother Oncol 1999: 53 (Suppl 1): S1-37. 